\title{
A new perspective for biological activities of novel hexahydroquinoline derivatives
}

\author{
Gökalp ÇETIN ${ }^{*}$ * (D), Busra ÇETIN 2 (D), Betül ÇOLAK ${ }^{3}$ (D), Melih AŞAN ${ }^{3}$ (D) , Gökcen BİRLIKK DEMİREL ${ }^{2}$ (D), \\ Demet CANSARAN-DUMAN 3 (D), Nefise AKÇELIK ${ }^{3}$ (D), Rahime ŞİMŞEK ${ }^{1}$ (iD)
}

1 Department of Pharmaceutical Chemistry, Faculty of Pharmacy, Hacettepe University, 06100, Sihhiye-Ankara, Turkey

2 Department of Chemistry, Polatlı Faculty of Arts and Sciences, Ankara Hacı Bayram Veli University, 06900, Polatl1Ankara, Turkey

3 Ankara University, Biotechnology Institute, 06135, Keçiören-Ankara, Turkey

* Corresponding Author. E-mail: gokalpcetin@hacettepe.edu.tr (G.Ç.); Tel. +90-534-276 4089.

Received: 02 November 2021 / Revised: 20 December 2021 / Accepted: 21 December 2021

ABSTRACT: Cancer is a systemic disease that occurs by various molecular mechanisms and its certain treatment has not been achieved yet. Antimicrobial drugs are the only option for the treatment of infections cause by bacteria and fungi. However, most microorganisms might develop resistantance against these drugs. 1,4-Dihydropyridine (1,4-DHP) is a partially saturated form of pyridine ring which shows calcium channel modulator activity. In addition to this activity of 1,4-DHPs and analog compounds such as hexahydroquinoline (HHQ), other activities have also been investigated. In this study, two new HHQ derivatives were synthesized to obtain a lead compound which has anticancer and antimicrobial activity. The structures of the synthesized compounds were proved by spectral methods. These HHQ derivatives compounds were conjugated to magnetic nanoparticles to investigate the changes in their anticancer and antimicrobial activities. For this purpose, firstly, we synthesized silica-coated magnetic nanoparticles. The silica-coated magnetic nanoparticles were conjugated with $\mathrm{HHQ}$ to enhance anticancer and antimicrobial activities. Anticancer and antimicrobial activity studies were carried out for both compounds and magnetic nanoparticle (MNP) forms. In addition, the physicochemical and pharmacokinetic properties, lipophilicity, water solubility and druglikeness of the compounds were determined in silico. Altogether, our data indicate that the new hexahydroquinoline derivatives have anticancer activity and the magnetic nanoparticle form led to increasing to this activity.

KEYWORDS: Hexahydroquinoline; magnetic nanoparticle (MNP); anticancer; antibacterial; antifungal; synthesis; spectra; Hantzsch reaction.

\section{INTRODUCTION}

According to the data of the World Health Organization (WHO), cancer is among the diseases of the highest cause of death in the world. It is stated that one out of every six deaths is due to cancer [1]. Breast cancer is a common disease among women worldwide [2]. Although different treatment options are available for breast cancer, the drug toxicity and drug resistance are the main cause of insufficient treatment. There is a need for novel molecules that act on these pathways because of the discovery of a wide variety of cancercausing mechanisms in recent years. Therefore, the discovery of new anticancer drugs was aimed for most of the drug research. Several novel candidate molecules have been suggested as effective agents for the treatment of breast cancer [3]. In recent years, studies have been carried out to prepare nanoparticle derivatives based on the approach that these compounds can be more effective by converting into nanoparticle forms [4].

In addition, infectious diseases are in the fourth place after ischemic heart diseases, stroke and chronic obstructive pulmonary disease [5]. New medications and effective treatments are needed because of the increasing difficulty in treating infectious diseases due to various reasons and resistance to existing drugs.

The medicinal chemistry gained an important ring system with the synthesis of 1,4-DHP ring by Arthur Hantzsch in 1882 [6]. After this date, the studies on the 1,4-DHP ring system continued increasingly and nifedipine was introduced to treatment as an antihypertensive drug in 1975 [7]. As a result of ongoing studies, while other derivatives such as amlodipine are used for treatment, similar active compounds were attempted to be obtained with all possible modifications in the 1,4-DHP ring [8]. In addition, studies on other

How to cite this article: Çetin G, Çetin B, Çolak B, Aşan M, Birlik Demirel G, Cansaran Duman D, Akçelik N, Şimşek R. A new perspective for biological activities of novel hexahydroquinoline derivatives. J Res Pharm. 2022; 26(1): 219-230. 
pharmacological activities of these compounds have gained speed and it has been found that these compounds may have other pharmacological activities. 1,4-DHP compounds possess antimicrobial, anti-inflammatory, antioxidant, antiatherosclerotic, anti-Alzheimer, anti-Parkinson, antituberculosis, antiulcer activity [9-16]. This group of compounds is also used to overcome multidrug resistance in tumor cells [17]. These compounds form a model for NAD-NADP (nicotinamide adenine dinucleotide-nicotinamide adenine dinucleotide phosphate) biological redox systems $[18,19]$.

The clinically success of the nifedipine molecule -the prototype of 1,4-DHP compounds with calcium channel blocker activity in antihypertensive therapy- has led to the synthesis of many new modified derivatives including condensed analogs [20]. Hexahydroquinoline obtained by fusing 1,4-DHP molecule with cyclohexane is the most common example of modifications. The proven experimental biological activity of hexahydroquinoline derivatives as a calcium channel blocker has led scientists to focus on these derivatives [21]. A large number of synthesized compounds; besides calcium channel blocker activity; have been screened for antimicrobial, antioxidant, antimalarial, antitumor, bronchodilator, geroprotective, antiastmatic and antiinflammatory activities [22]. The cytotoxic effect of the synthesized hexahydroquinoline derivatives was investigated in studies conducted by some research groups and it has been proved that hexahydroquinoline derivatives show promising anticancer activity by various mechanisms [23]. In addition, many studies have investigated antibacterial and antifungal activities of compounds having hexahydroquinoline ring system [2426]. Today, one of the the most important cancer treatment method is chemotherapy with other treatment options such as radiotherapy and gene theraphy. Because of suppression of the immune system, microbial infections can be seen in patients receiving chemotherapy [27]. Applying antimicrobial treatment in addition to chemotherapy causes secondary diseases in patients with liver and kidney dysfunction. Therefore, a compound that exhibits anticancer and antimicrobial activity is advantageous from therapy and patient compliance perspective [28].

It has been experimentally proven that nanoparticle formulations increase biocompatibility, pharmacokinetic and pharmacological properties. Based on this, studies have been conducted in which an improvement in activity is observed by converting existing anticancer drugs, such as doxorubicin, into magnetic nanoparticle form in the treatment [29]. Also in recent studies, the compounds with known antimicrobial activity were conjugated with magnetic nanoparticle and the activities of the particle-conjugated compounds were reexamined. In these studies, it has been found that the magnetic particle-conjugated compounds show additive or synergistic activity according to their free form [30].

Fluoro substitution into the structure of the compounds is a strategic approach to increase the potency of the drug in recent years. Fluorine substitution into a molecule; affects conformation, molecular target selectivity by affecting $\mathrm{pKa}$, membrane permeability, hydrophobic interactions, lipophilicity, pharmacokinetic characteristics or a combination of these properties. Fluoro is an important atom for drug metabolism [31].

Although improvements in diagnosis and options of therapy, the incidence of breast cancer is still at high level [32]. Chemotherapeutics used for breast cancer treatment have toxic effects and the patient can develop resistance to chemotherapeutics during time [33].

In the current study, the effect of new hexahydroquinoline derivatives were analyzed to develope novel candidate molecules for treatment of breast cancer. In order to do that two new hexahydroquinoline derivatives were synthesized and their structure was proved by spectral methods (IR, 1H-NMR, 13C-NMR, HRMS and elemental analysis). In the following process, anticancer activity of the compounds were evaluated by using MCF-7 breast cancer cell line. In addition antibacterial and antifungal activity of the compounds were determined. We also conjugated the compounds with magnetic nanoparticle to reveal the possible contribution to the mentioned activity.

\section{RESULTS AND DISCUSSION}

\subsection{Chemistry}

The compounds were synthesized by Hantzsch reaction in a conventional manner. The structure of the compounds were elucidated by IR, ${ }^{1} \mathrm{H}-\mathrm{NMR},{ }^{13} \mathrm{C}-\mathrm{NMR}$ and elemental analysis. The structure and properties of the target compounds were given in Table 1.

In the IR spectra, characteristic N- H stretching bonds were observed at 3277 and $3297 \mathrm{~cm}^{-1}$. The characteristic $\mathrm{C}=\mathrm{O}$ (ester) and $\mathrm{C}=\mathrm{O}$ (ketone) bonds were seen at 1696, 1697 and 1644, $1651 \mathrm{~cm}^{-1}$, respectively. In the ${ }^{1} \mathrm{H}-\mathrm{NMR}$ spectra, the signals of two methyl groups at 6 th position of $\mathrm{HHQ}$ ring were recorded at 0.8 and $0.9 \mathrm{ppm}$ separately and as singlets. The HHQ ring's 4th position peaks were seen as singlet at 4.89 and 4.91 ppm respectively for RG115 and RG127. The aromatic protons of the phenyl ring were seen at 7.15-7.53 and 
the protons of N-H protons were observed at 9.20 and $9.23 \mathrm{ppm}$. These peaks confirmed that HHQ ring was successfully synthesized. The reason for the multiplet of methylene peak in the ethyl derivative is the longrange interactions that occur due to the chiral carbon of the 4th position of HHQ.

Table 1. Structure of the synthesized compounds.

\begin{tabular}{|c|c|c|c|c|c|}
\hline & $\begin{array}{r}\mathrm{H}_{3} \mathrm{C} \\
\mathrm{H}_{3} \mathrm{C}\end{array}$ & $\mathrm{O}^{\mathrm{A1}}$ & $\mathrm{CH}_{3}^{-}$ & & \\
\hline Compound & $\mathrm{Ar}$ & $\mathbf{R}$ & m.p. ( $\left.{ }^{\circ} \mathrm{C}\right)$ & Empirical formula & M.W. \\
\hline RG115 & $\begin{array}{l}\text { 2-fluoro-5- } \\
\text { trifluoromethylphenyl }\end{array}$ & Ethyl & $268-270$ & $\mathrm{C}_{22} \mathrm{H}_{23} \mathrm{~F}_{4} \mathrm{NO}_{3}$ & 425.16 \\
\hline RG127 & $\begin{array}{l}\text { 3-fluoro-5- } \\
\text { trifluoromethylphenyl }\end{array}$ & Isopropyl & $213-215$ & $\mathrm{C}_{23} \mathrm{H}_{25} \mathrm{~F}_{4} \mathrm{NO}_{3}$ & 439.18 \\
\hline
\end{tabular}

In the ${ }^{13} \mathrm{C}-\mathrm{NMR}$ spectra, each carbon atom appears only as a single resonance, the number of the signals fitted exactly the number of carbon atoms. The signals belonging to carbonyl groups at 5 th position of the HHQ ring were seen at $200 \mathrm{ppm}$ while the ester carbonyl groups were recorded at about $166 \mathrm{ppm}$. While the carbons in the 3rd and 4a positions give a peak around $100 \mathrm{ppm}$, the carbon atoms in the 2nd and 8a positions give a peak around $150 \mathrm{ppm}$ due to the inductive effect of nitrogen, which is an electronegative atom.

The HRMS spectra of the compounds were recorded using the electrospray ionisation-Q-TOF technique. Molecular ion peaks $(\mathrm{M}+\mathrm{H})$ were seen in the spectra of both compounds. These peaks are also base peaks in the spectra. In further fragmentation, the ions were formed by the cleavage of the ester group, Oalkyl function and phenyl ring. Aromatisation of the DHP ring to the pyridine analogue was also realised. Elemental analysis results were within $\pm 0.4 \%$ of the theoretical values for both compounds.

\subsection{Nanoparticle results}

The chemical characterization of Fe3O4@SiO2@RG115 and Fe3O4@SiO2@RG127 nanoparticles was performed by ATR-FTIR and UV-Vis analysis. The chemical composition of each step of the fabrication of the RG115-MNPs and RG127 MNPs were identified by ATR-FTIR analysis (Figure 1). The specific $\mathrm{C}=\mathrm{O}$ stretching band and ketone $\mathrm{C}=\mathrm{O}$ streching band for both RG115 and RG127 were observed at $1690 \mathrm{~cm}^{-1}$ and at $1640 \mathrm{~cm}^{-}$ 1 , respectively as seen in Figure (1A-1B). Moreover, when the UV-Vis spectrums of the RG115-MNPs (Figure 1C) and RG127-MNPs (Figure 1D) were investigated, the absorption band for the spesific $\Pi-\Pi^{*}$ transitions of the hexahydroquinoline derivative compounds was observed at around $350 \mathrm{~nm}$. According to these results it can be said that both RG115 and RG127 compound were successfully conjugated to the silica coated magnetic nanoparticles.

The morphology of the RG115 conjugated Fe3O4@SiO2 nanoparticles was clarified by TEM image (Figure 2A). As seen in TEM images, the magnetic core and the silica layer of the particles can be seen clearly. In addition the presence of RG115 coating was also observed as a very thin layer. The magnetic Fe3O4 core was measured as $150 \mathrm{~nm}$ and almost $50 \mathrm{~nm}$ thickness of a silica shell formation was observed on the magnetic core. In addition, the thickness of RG115 coating was measured about $5 \mathrm{~nm}$.

The surface charge of the particle is an another proof of the identify the covering process of the particles. Moreover, the zeta-potential values also important for the biomedical applications of the particles. To reveal the change of the surface charge of the particles before and after the RG115 and RG127 conjugation, we have measured the zeta-potential values of the particles. The releated diagram was given in Figure 2B. The zetapotential values of Fe3O4@SiO2, Fe3O4@SiO2@ RG115, and Fe3O4@SiO2@RG127 were measured as -16 \pm 1.45 , $-30 \pm 1.98$ and $-27 \pm 1.55 \mathrm{mV}$, respectively. This results indicate that the substitution of fluorine containing RG115 and RG127 compounds affected the negativity of zeta potential for the Fe3O4@SiO2@RG115 NPs, (B) Fe3O4@SiO2@RG127 NPs [37]. 

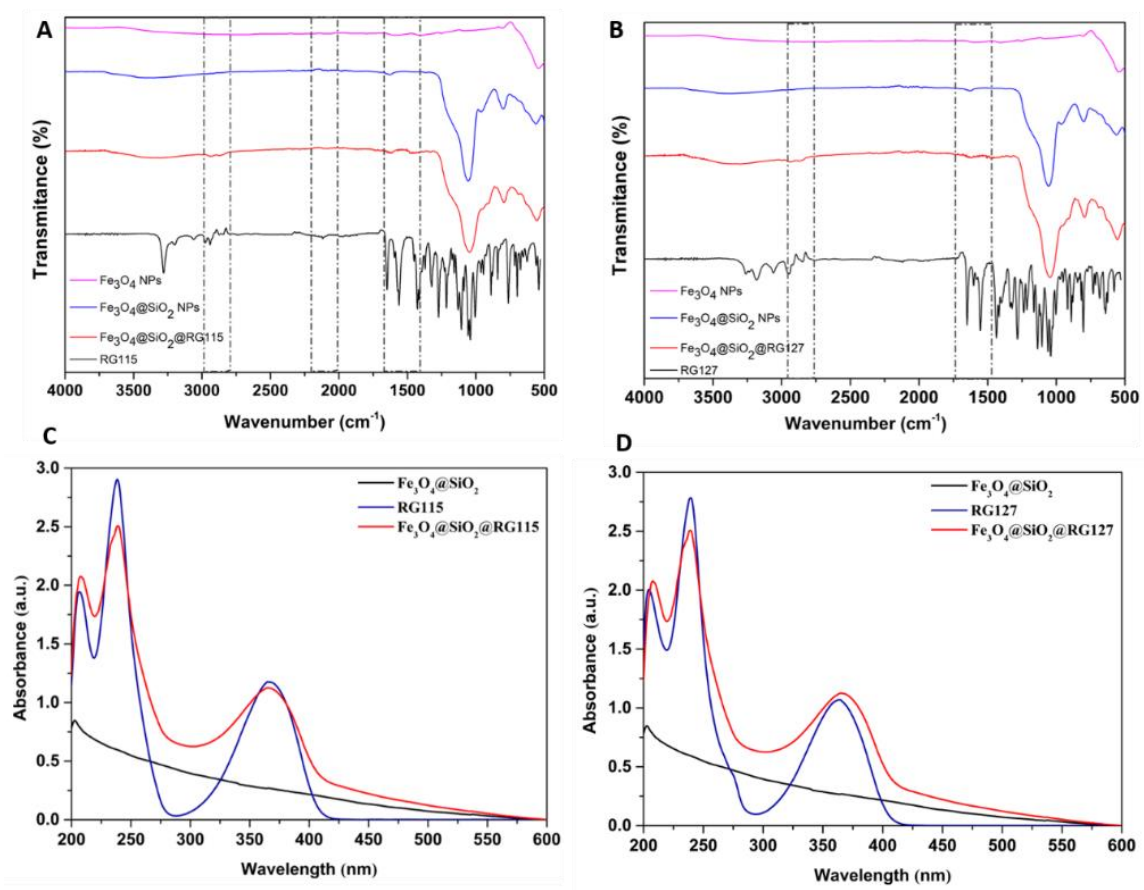

Figure 1. ATR-FTIR spectrum of (A) Fe3O4@SiO2@RG115 NPs, (B) Fe3O4@SiO2@RG127 NPs; UV-Vis spectrum of (C) Fe3O4@SiO2@RG115 NPs and (D) Fe3O4@SiO2@RG127 NPs.

A

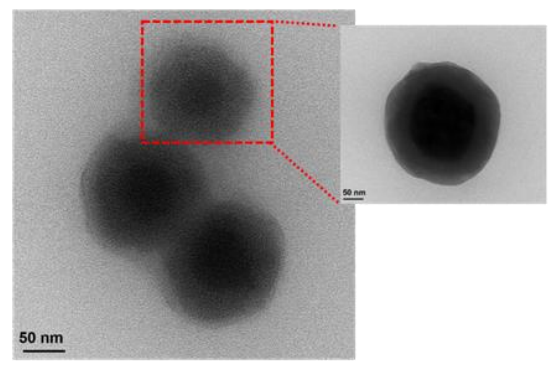

B

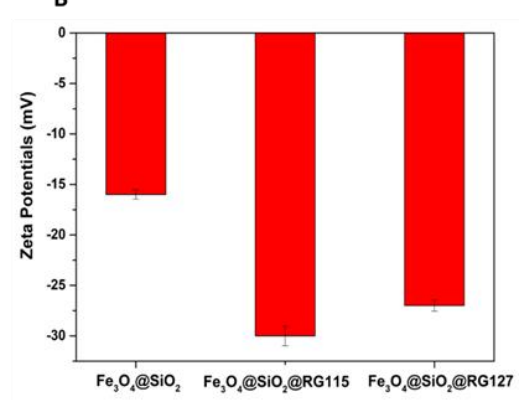

Figure 2. (A)TEM images of hexahydroquinoline derivative conjugated Fe3O4@SiO2 nanoparticles and high resolution TEM of single nanoparticle, (B) Zeta-potentials of hexahydroquinoline derivative conjugated nanoparticles.

\subsection{Anticancer activity results}

To determine anticancer effects of the synthesized compounds and their MNP forms, xCELLigence RTCA (Real Time Cell Analyzer) system was used for MCF-7 cells. RG115 did not cause cytotoxicity at examined all concentrations (1,5 and $10 \mathrm{mg} / \mathrm{ml}$ ) (Figure 3A) but this compound showed anticancer effect on MCF-7 cells after coating with nanoparticles (RG115MNP) (Figure 3B). While $10 \mathrm{mg} / \mathrm{ml}$ of sample RG115MNP showed cytotoxic effect, $1 \mathrm{mg} / \mathrm{ml}$ and $5 \mathrm{mg} / \mathrm{ml}$ of sample RG115MNP was determined to anticancer effect on MCF-7 breast cancer cells. The concentration of 1,5 and $10 \mathrm{mg} / \mathrm{ml}$ of RG127 resulted to cause a same anticancer effect compared with RG127MNP on MCF-7 cells (Figure 3C and 3D). These findings clearly indicated that RG115MNP, RG127 and RG127MNP have a potent anticancer effect against MCF-7 breast cancer cells (Table 2).

\subsection{Antimicrobial activity results}

Antimicrobial activity of HHQ derivatives compounds covered and noncovered MNPs were determined against representative strains of Gram positive, Gram negative bacteria and a fungal strain C. albicans. To identify the antimicrobial activity, 4 compounds (RG115, RG115MNP, RG127, RG127MNP) were screened at a final concentration of $32 \mathrm{mg} / \mathrm{mL}$ in 96 well plates. The obtained Z-scores of all compounds were shown in Figure 4. Using a Z-score of 2.0 as the threshold, none of the compounds had a Z-score equal or more than 2.0, suggesting that tested compounds had not got an antimicrobial activity on any of the 12 different microorganisms. 

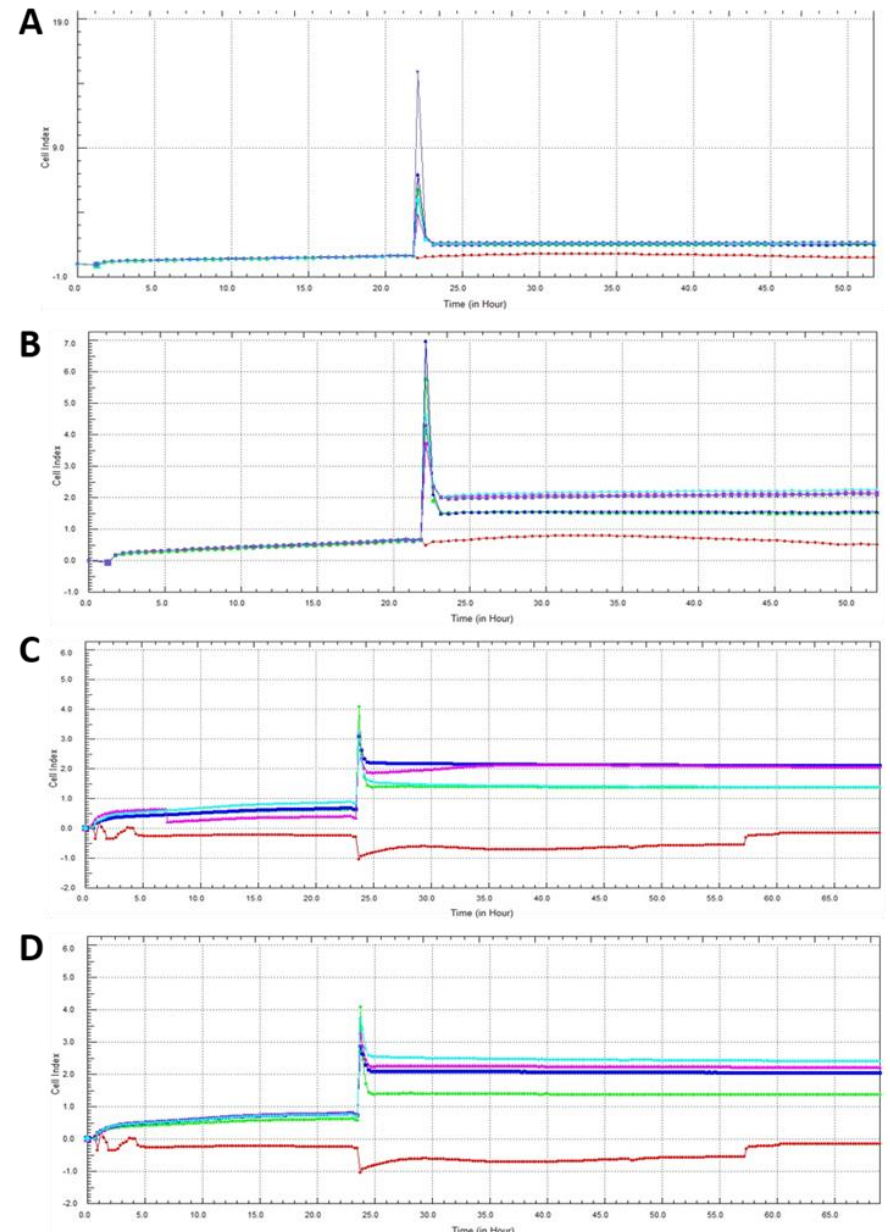

Figure 3. Real time cell analysis of antiproliferative effect of RG115, RG115MNP, RG127 and RG127MNP. The cell index values for 1, 5 and $10 \mathrm{mg} / \mathrm{ml}$ of RG115 (A); RG115MNP (B), RG127 (C), RG127MNP (D) on MCF-7 cells are shown. The concentrations represented by different colors in Figure 3 (Red: Positive control, Green and Dark blue: DMSO, Pink: 1mg/ml, Turquoise: $5 \mathrm{mg} / \mathrm{ml}$, Purple: $10 \mathrm{mg} / \mathrm{ml}$ ).

Table 2. The ratio of anti-cancer effect in RD115, RG115NP, RG127, RG127NP compounds (\%).

\begin{tabular}{|c|c|c|c|}
\hline \multicolumn{4}{|c|}{ Concentrations } \\
\hline Compounds & $1 \mathrm{mg} / \mathrm{ml}$ & $5 \mathrm{mg} / \mathrm{ml}$ & $10 \mathrm{mg} / \mathrm{ml}$ \\
\hline RG115 & $\% 48.9 \pm 0.01$ & $\% 53.9 \pm 0.03$ & $\% 59.3 \pm 0.02$ \\
\hline RG115NP & $\%$ 65.7 \pm 0.01 & $\% 77.8 \pm 0.01$ & $\% 91.5 \pm 0.01$ \\
\hline RG127 & $\% 57.8 \pm 0.02$ & $\% 64.9 \pm 0.01$ & $\% 78.4 \pm 0.02$ \\
\hline RG127NP & $\% 59.6 \pm 0.01$ & $\% 67.5 \pm 0.01$ & $\% 79.9 \pm 0.01$ \\
\hline
\end{tabular}

The resazurin activity of each compound was normalized to cell viability before the Z-score was calculated. The results showed that none of the tested compounds exhibited antimicrobial activity any of the tested concentrations. Although, covered counterparts exhibited slightly more efficiency compared to noncovered versus, this activity increase was not statistically significant. As a result of our experiments, there was no significant increase in the antibacterial and antifungal activity of the compounds immobilized into the nanoparticle. It was found that this new formulation designed for compounds did not contribute positively to antimicrobial activity.

\subsection{In silico prediction of ADME and drug-likeness properties}

The in silico physicochemical and pharmacokinetic properties, lipophilicity, water solubility and druglikeness of the compounds were determined by SwissAdme [38]. The calculated average LogP values are 4.85 for compound 1 and 5.15 for compound 2. Oral usage and absorption of the compounds depend on the solubility indicated by LogS. The polar surface area and topological polar surface area, which is an important criteria for the compounds to cross biological barriers such as the blood-brain barrier, should be less than 140 
$\AA$ A 2. Calculated total polar surface area (TPSA) values are $55.4 \AA 2$ for both compounds. Intestinal absorption, which is an important parameter for drug candidate molecules, is calculated with the formula \% ABS $=109$ (0.345 x TPSA) [39]. According to this calculation, both compounds have $89 \%$ intestinal absorption. The number of rotatable bonds must be less than ten for the compounds to bind to biological targets. The molar refractive index, which should be less than 130, is 106.43 for RG115 and 111.24 for RG127. Although Pglycoprotein (P-gp), which is found in many healthy tissues and some tumor cells, is responsible for the pharmacokinetic and toxicokinetic properties of drug molecules, it causes multi-drug resistance.

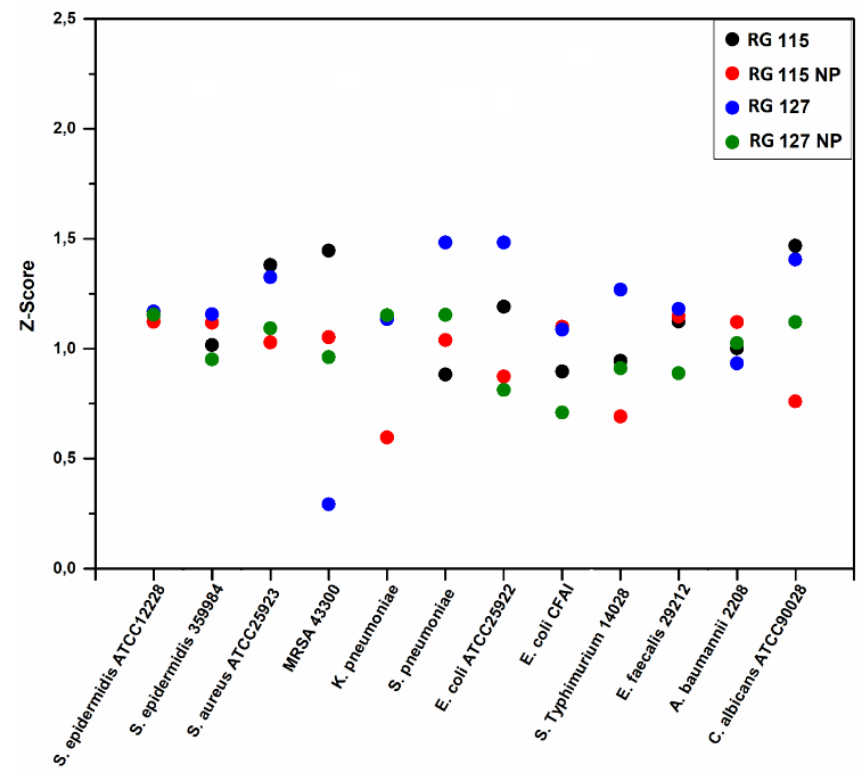

Figure 4. Z-scores of 4 compounds (RG115, RG115MNP, RG127, RG127MNP) following a primary screening.

Based on our in silico calculations, both compounds are not substrates for P-gp [40]. While both compounds are inhibitor of CYP2C19, CYP2C9 and CYP3A4, none of them are inhibitor of CYP1A2 and CYP2D6. Boiled-egg (Brain Or IntestinaL EstimateD permeation predictive model) model is predictive in silico tool for intestinal absorption and blood-brain barrier penetration. According to this model, the compounds located in the yellow area display high intestinal absorption and brain penetration, the white area display only intestinal absorption and the gray area is low intestinal absorption zone [41]. Aspect to the boiled-egg, our compounds are located in the HIA (Human Intestinal Absorption) region.

Lipinski's and Veber's rules are applied to both compounds according to drug-likeness properties. Compound 2 has a violation of Ghose, Egan and Muegge parameters, while compound 1 violates a rule only in Ghose and Egan. Bioavailability score of both compounds is 0.55. Both compounds have high gastrointestinal absorption when evaluated in terms of pharmacokinetic properties. Their solubility in water ranges from poor to moderate. Considering all these values, it can be said that the compounds have similar properties with the oral drugs currently used in the treatment. As a result whole compounds have high potential to be drug (Table 3 ).

\section{CONCLUSION}

In this study, we synthesized new hexahydroquinoline derivatives and their magnetic nanoparticle (MNP) forms to investigate their anticancer and antimicrobial activity. Here, we demonstrated the potential anticancer role of both synthesized compounds and their MNP forms by examining its effects on breast cancer cells. For the first time, we showed that anticancer activity of all tested compounds in breast cancer cells. These results may provide new insights into the anticancer effect of hexahydroquinoline derivatives in the management of breast cancer. Conjugation of synthesized hexahydroquinoline derivatives to magnetic nanoparticles contributed positively to anticancer activity. While both compounds showed anticancer activity at a dose of 1 and $5 \mathrm{mg} / \mathrm{ml}$, RG127 was also active at a dose of $10 \mathrm{mg} / \mathrm{ml}$. Significant results could not be obtained in the antimicrobial activity studies that we conducted on the basis that the compounds can be dualacting. In the future studies, these compound will be tested by combining antibiotics, used at the treatment of infectious diseases in order to investigate synergetic effects. By using in combinations, it may be possible to 
dicrease the dosage of antibiotics in treatment to elucidate side effects. Also calculating drug-likeness and other parameters belonging to newly synthesized compounds showed that these derivatives can be considered as precursor compounds for new group of anticancer agents. These results showed us that the new formulation we obtained by converting the compounds into nanoparticle form increased the activity. The contribution to anticancer activity of the compounds' nanoparticle forms can be studied with a larger number of compounds in further studies.

Table 3. In silico ADME prediction of RG115 and RG127.

\begin{tabular}{ccc}
\hline ADME properties & RG115 & RG127 \\
\hline MW (Molecular weight) $\leq \mathbf{5 0 0}$ & 425.42 & 439.44 \\
CLP (cLOGP) < 5 & 4.85 & 5.15 \\
LogS (Solubility) $\geq \mathbf{- 4}$ & -5.61 & -6.06 \\
RB (Rotatable bonds) $\leq \mathbf{1 0}$ & 5 & 5 \\
HD (Hidrogen donors) $\leq \mathbf{5}$ & 1 & 1 \\
HA (Hidrogen acceptors) $\leq \mathbf{1 0}$ & 7 & 7 \\
MR (Molar refractivity) 40-130 & 106.43 & 111.24 \\
\% ABS & 89.88 & 89.88 \\
TPSA (Topological polar & 55.40 & 55.40 \\
surface area) $\leq 140$ §2 & High & High \\
GI Aborption & No & No \\
BBB penetration & No & No \\
P-gp substrate & No & No \\
CYP1A2 inhibitor & Yes & Yes \\
CYP2C19 inhibitor & Yes & Yes \\
CYP2C9 inhibitor & No & No \\
CYP2D6 inhibitor & Yes & Yes \\
CYP3A4 inhibitor & 0.56 & 0.55 \\
Bioavailability score & &
\end{tabular}

\section{MATERIALS AND METHODS}

\subsection{Chemistry}

All chemicals used were purchased from Aldrich (USA) and were used without further purification. Purity of the synthesized compounds was checked by thin layer chromatography (TLC) on Merck aluminum sheets (Germany), silica gel 60 F254, mobile phase ethyl acetate:n-hexane (1:1), and UV absorbing spots were detected under short-wavelength $(254 \mathrm{~nm})$ light (Camag UV Cabinet, Germany). Melting points were determined on a Thomas Hoover capillary melting point apparatus (USA) and uncorrected. Infrared spectra (IR) were recorded on Perkin Elmer Spectrum BX FT-IR (UK) equipped with MIRacle ATR accessory (PIKE Technologies, USA) and were reported in $\mathrm{cm}^{-1}$. 1H-NMR and 13C-NMR spectra were taken in dimethyl sulfoxide (DMSO-d6) solution on a Bruker, $500 \mathrm{MHz}$ high performance digital FT-NMR spectrometer (USA) using tetramethylsilane (TMS) as internal standard. Chemical shifts were reported in parts per million (ppm). HRMS was realized by Agilent 6530 Accurate-Mass Q-TOF. Elemental analysis (C, H and N) was obtained on a Leco CHNS-932 Elemental Analyzer with accuracy $0.4 \%$.

4.1.1. General synthesis of alkyl 2,6,6-trimethyl-4-(disubstitutedphenyl)-5-oxo-1,4,5,6,7,8-hexahydroquinoline-3carboxylate derivatives

The compounds were synthesized via Hantzsch reaction. 4,4-dimethylcyclohexane-1,3-dione (1 mmol), disubstituted benzaldehyde derivative $(1 \mathrm{mmol})$, appropriate alkyl acetoacetate $(1 \mathrm{mmol})$ and ammonium acetate $(5 \mathrm{mmol})$ were refluxed for eight hours in absolute methanol. Reaction mixture was monitored by TLC and after completion of the reaction, it was cooled to room temperature. The obtained precipitate was filtered and crystallized from ethanol for further purification. The synthetic route was shown in Fi.

Ethyl 2,6,6-trimethyl-4-(2-fluoro-5-trifluoromethylphenyl)-5-oxo-1,4,5,6,7,8-hexahydroquinoline-3carboxylate (RG115). The compound was obtained by the reaction of 4,4-dimethylcyclohexane-1,3-dione, 2fluoro-5-trifluorobenzaldehyde, ethyl acetoacetate and ammonium acetate in $10 \mathrm{~mL}$ methanol. Yellowish solid, m.p: 268-270, yield: 76\%. IR (v, cm-1) $3297(\mathrm{~N}-\mathrm{H}), 1696$ (C=O, ester), 1644 (C=O, ketone). ${ }^{1} \mathrm{H}-\mathrm{NMR}(\delta$, DMSO-d 6 ): 0.89 (3H; s; 6- $\left.\mathrm{CH}_{3}\right), 0.97\left(3 \mathrm{H} ; \mathrm{s} ; 6-\mathrm{CH}_{3}\right), 1.14\left(3 \mathrm{H} ; \mathrm{t} ; \mathrm{J}=6.8 \mathrm{~Hz}, \mathrm{CH}_{2} \mathrm{CH}_{3}\right), 1.69-1.73(2 \mathrm{H} ; \mathrm{m}$; quinoline $\left.\mathrm{H}^{7}\right), 2.27\left(3 \mathrm{H} ; \mathrm{s} ; 2-\mathrm{CH}_{3}\right), 2.47-2.52\left(2 \mathrm{H} ; \mathrm{m} ;\right.$ quinoline $\left.\mathrm{H}^{8}\right)$, 3.89-3.94 $\left(2 \mathrm{H} ; \mathrm{m} ; \mathrm{COOCH}_{2} \mathrm{CH}_{3}\right) ; 4.89(1 \mathrm{H} ; \mathrm{s}$; quinoline 
$\left.\mathrm{H}^{4}\right), 7.23\left(\mathrm{H}, \mathrm{t} ; \mathrm{J}=9.2 \mathrm{~Hz}\right.$, aromatic), 7.48-7.53 (2H, m; aromatic) $9.2(1 \mathrm{H}, \mathrm{s} ; \mathrm{NH}) .{ }^{13} \mathrm{C}-\mathrm{NMR}\left(\mathrm{\delta}, \mathrm{DMSO}-\mathrm{d}_{6}\right): 14.3$ $\left(\mathrm{COOCH}_{2} \mathrm{CH}_{3}\right), 18.6\left(2-\mathrm{CH}_{3}\right), 23.3(\mathrm{C}-8), 24.6\left(6-\mathrm{CH}_{3}\right), 25.0\left(6-\mathrm{CH}_{3}\right), 33.3(\mathrm{C}-7), 34.5(\mathrm{C}-4), 40.1$ (C-6), 59.5 $\left(\mathrm{COOCH}_{2} \mathrm{CH}_{3}\right), 101.5$ (C-3), 108.0 (C-4a), 116.8, 123.4, 125.3, 128.4, 136.0, 163,4 (phenyl carbons), 125,4 $\left(\mathrm{CF}_{3}\right)$ 146.5 (C-2), 150.7 (C-8a), $166.9\left(\mathrm{COOCH}_{2} \mathrm{CH}_{3}\right), 199.7$ (C-5). HRMS (ESI/Q-TOF) m/z: [M+H] ${ }^{+}$Calcd for $\mathrm{C}_{22} \mathrm{H}_{23} \mathrm{~F}_{4} \mathrm{NO}_{3}$ 426.1648; Found 426.1707, 380.128, 262.145, 234.114. Anal. Calcd. for $\mathrm{C}_{22} \mathrm{H}_{23} \mathrm{~F}_{4} \mathrm{NO}_{3} ; \mathrm{C}, 62.11 ; \mathrm{H}$, $5.45 ; \mathrm{N}, 3.29$. Found: C, 61.85; H, 5.87; N, 3.40.

Isopropyl 2,6,6-trimethyl-4-(3-fluoro-5-trifluoromethylphenyl)-5-oxo-1,4,5,6,7,8-hexahydroquinoline3-carboxylate (RG127). The compound was obtained by the reaction of 4,4-dimethylcyclohexane-1,3-dione, 3fluoro-5-trifluorobenzaldehyde, isopropyl acetoacetate and ammonium acetate in $10 \mathrm{~mL}$ methanol. Yellowish solid, m.p: 213-215 yield: 69\%. IR ( $\left.\mathrm{cm}^{-1}\right) 3277$ (N-H), 1697 ( $\mathrm{C}=\mathrm{O}$, ester), 1651 ( $\mathrm{C}=\mathrm{O}$, ketone), ${ }^{1} \mathrm{H}-\mathrm{NMR}$ ( $\delta$, DMSO$\left.\mathrm{d}_{6}\right): 0.88(3 \mathrm{H} ; \mathrm{s} ; 6-\mathrm{CH} 3), 0.99\left(3 \mathrm{H} ; \mathrm{s} ; 6-\mathrm{CH}_{3}\right), 1.00\left(3 \mathrm{H}, \mathrm{d}, \mathrm{CH}\left(\mathrm{CH}_{3}\right)_{2}\right), 1.17\left(3 \mathrm{H}, \mathrm{d}, \mathrm{J}=6.4 \mathrm{~Hz} \mathrm{CH}\left(\mathrm{CH}_{3}\right)_{2}\right), 1.71-1.76$ $\left(2 \mathrm{H}, \mathrm{m}\right.$, quinoline $\left.\mathrm{H}^{7}\right), 2.30\left(3 \mathrm{H}, \mathrm{s}, 2-\mathrm{CH}_{3}\right), 2.50-2.58\left(2 \mathrm{H}, \mathrm{m}\right.$, quinoline $\left.\mathrm{H}^{8}\right), 4.81-4.85\left(1 \mathrm{H}, \mathrm{m}, \mathrm{CH}\left(\mathrm{CH}_{3}\right)_{2}\right), 4.91$ $\left(1 \mathrm{H}, \mathrm{s}\right.$, quinoline $\left.\mathrm{H}^{4}\right), 7.15(\mathrm{H}, \mathrm{d}, \mathrm{J}=9.65 \mathrm{~Hz}$, aromatic), $7.33(\mathrm{H}, \mathrm{s}$, aromatic), $7.38(\mathrm{H}, \mathrm{d}, \mathrm{J}=8.6 \mathrm{~Hz}$, aromatic), $9.23(1 \mathrm{H}, \mathrm{s}, \mathrm{NH}) .{ }^{13} \mathrm{C}-\mathrm{NMR}\left(\mathrm{\delta}, \mathrm{DMSO}-\mathrm{d}_{6}\right): 18.7\left(2-\mathrm{CH}_{3}\right), 21.7\left(\mathrm{COOCH}\left(\mathrm{CH}_{3}\right)_{2}\right), 22.2\left(\mathrm{COOCH}\left(\mathrm{CH}_{3}\right)_{2}\right), 23.3(\mathrm{C}-8)$, $24.5\left(6-\mathrm{CH}_{3}\right), 25.3\left(6-\mathrm{CH}_{3}\right), 34.5(\mathrm{C}-7), 37.1(\mathrm{C}-6), 40.4(\mathrm{C}-4), 66.7\left(\mathrm{COOCH}\left(\mathrm{CH}_{3}\right)_{2}\right), 102.6(\mathrm{C}-3), 108.6(\mathrm{C}-4 \mathrm{a}), 110.6$, $118,6,120.8,122.8,130.2,161,6$ (phenyl carbons), $125.0\left(\mathrm{CF}_{3}\right), 151.0(\mathrm{C}-2), 152.9(\mathrm{C}-8 \mathrm{a}), 166.3\left(\mathrm{COOCH}\left(\mathrm{CH}_{3}\right)_{2}\right)$, 200.0 (C-5). HRMS (ESI/Q-TOF) m/z: $[\mathrm{M}+\mathrm{H}]^{+}$Calcd for $\mathrm{C}_{23} \mathrm{H}_{25} \mathrm{~F}_{4} \mathrm{NO}_{3}$ 440.1804; Found 440.1859, 398.139, 381.298, 234.114. Anal. Calcd. for $\mathrm{C}_{23} \mathrm{H}_{25} \mathrm{~F}_{4} \mathrm{NO}_{3} ; \mathrm{C}, 62.86 ; \mathrm{H}, 5.73 ; \mathrm{N}, 3.19$. Found: $\mathrm{C}, 62.77 ; \mathrm{H}, 5.91 ; \mathrm{N}, 3.26$.

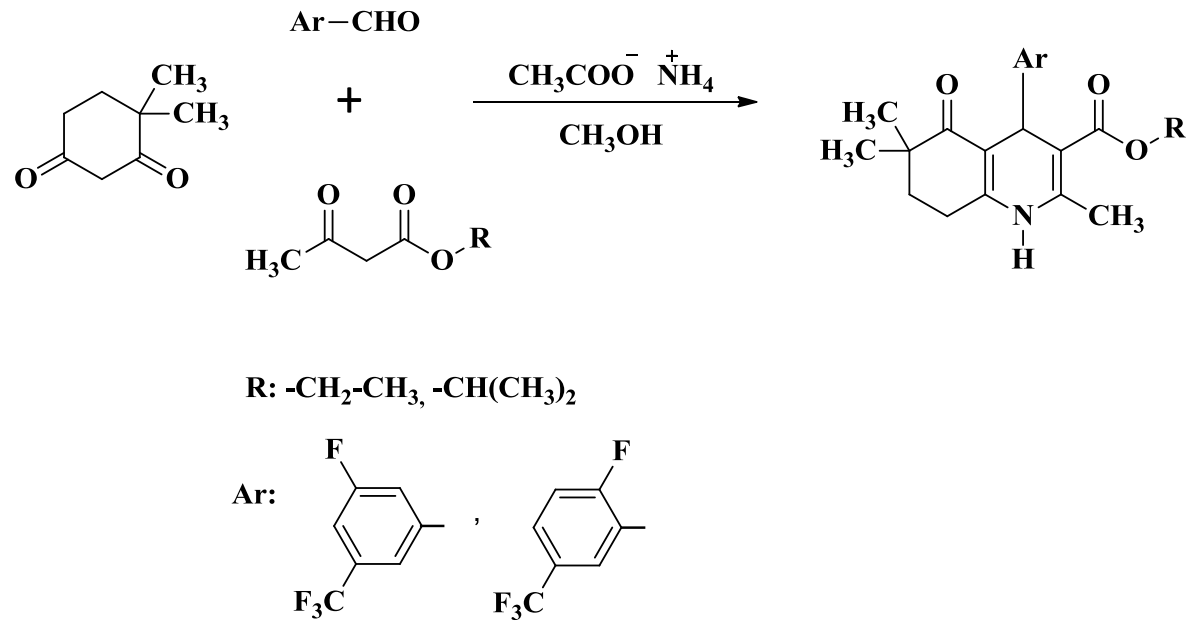

Figure 5. Synthesis of the target compounds.

\subsubsection{The transformation of $H H Q$ molecules to nanoparticles}

Synthesis of silica-coated magnetic nanoparticles: Magnetic $\mathrm{Fe}_{3} \mathrm{O}_{4}$ nanoparticles (NP) were synthesized by using coprecipitation method as described previously [34]. Briefly, a solution of $\mathrm{FeCl}_{3} \cdot 6 \mathrm{H}_{2} \mathrm{O}(0.5 \mathrm{~g})$ and $\mathrm{FeCl}_{2}$ $.4 \mathrm{H}_{2} \mathrm{O}(0.18 \mathrm{~g})$ in $20 \mathrm{~mL}$ deionized water (DI) was heated at $40^{\circ} \mathrm{C}$ for $20 \mathrm{~min}$ with vigorous stirring. After that, $5 \mathrm{M} \mathrm{NaOH}(1.5 \mathrm{~mL})$ was slowly added to the solution and a black precipitate was obtained. The black solution was stirred at room temperature (RT) for $2 \mathrm{~h}$. Then the magnetic nanoparticles were collected by centrifuge and washed with DI water and ethanol several times.

The synthesized magnetic nanoparticles were coated with a silica layer using the following procedure. The $\mathrm{Fe}_{3} \mathrm{O}_{4} \mathrm{NPs}(10 \mathrm{mg})$ were dispersed in a solution of ethanol $(8 \mathrm{~mL})$ and DI water $(2 \mathrm{~mL})$. This solution was sonicated for $20 \mathrm{~min}$. Subsequently, $100 \mu \mathrm{L}$ of tetraethylorthosilicate (TEOS) was added to the solution under vigorous stirring at $\mathrm{RT}$. Then, $2 \mathrm{M} \mathrm{NaOH}$ solution was added to the mixture drop by drop while the solution stirring. This solution was stirred for an additional $6 \mathrm{~h}$ at $\mathrm{RT}$. At the end of this time, the $\mathrm{Fe}_{3} \mathrm{O}_{4} @ \mathrm{SiO}_{2} \mathrm{NPs}_{\text {were }}$ collected by a simple magnet and washed several times.

Synthesis of HHQ conjugated silica-coated magnetic nanoparticles: The silica coated magnetic nanoparticles were conjugated with HHQ molecules. For this purpose, firstly, the silica coated magnetic nanoparticles were functionalized by an epoxy-silane agent, 3-Glycidyloxypropyltrimethoxysilane (GPTS), to conjugate HHQ molecules on the particle surface. Briefly, $5 \mathrm{mg}$ of silica coated magnetic nanoparticle was dispersed into $5 \mathrm{ml}$ DMSO and the solution was sonicated for $20 \mathrm{~min}$. After that $20 \mu \mathrm{L}$ GPTS was added to the particle solution. This solution was stirred for $6 \mathrm{~h}$ at RT to prepare epoxy-functionalized silica-coated magnetic nanoparticles 
[35]. At the end of the time, a $5 \mathrm{~mL}$ solution of $1 \mathrm{mg} / 1 \mathrm{~mL}$ HHQ compound which is prepared in DMSO was added into the solution of GPTS-functionalized particle. This solution was stirred for another $24 \mathrm{~h}$ at RT to conjugate HHQ molecules on the magnetic nanoparticles. The HHQ conjugated magnetic nanoparticles were collected by a simple magnet. The collected particles washed with DI Water several times and then dried in a vacuum oven at RT. The functionalized particles were characterized by using ATR-FTIR, UV-Vis Spectroscopy. Moreover, the particles morphology was identified by TEM image.

\subsubsection{The determination of biological activities of HHQ molecules}

\section{Anticancer activity studies}

Cell culture: MCF-7 breast cancer cells were obtained ATCC and cultured in Dulbecco's Modified Eagle Medium (DMEM, Sigma). The culture media was added with 10\% fetal bovine serum (FBS, Gibco) and 1\% Penicillin- streptomycin (Sigma). Cells were grown at $37^{\circ} \mathrm{C}$ in in a humidified atmosphere containing $5 \% \mathrm{CO}$. After the confluency, cells were cultivated in E-plate of real time cell analyzer (RTCA) system.

Determination of anti-growth effect by the real time cell analyzer (RTCA) system: Cell proliferation was also continuously monitored using the xCELLigence RTCA Instrument (Roche, Germany). MCF-7 cells seeded at a density of $1 \times 10^{4}$ cells per well of e-plate (xCELLigence RTCA, Roche, Germany). After $24 \mathrm{~h}$, synthesized compounds and their MNP forms were added to the wells at different concentrations $(1,5$ and $10 \mathrm{mg} / \mathrm{ml})$. Proliferation was monitored every $1 \mathrm{~h}$ and time dependent cell index $(\mathrm{CI})$ graph was produced by the device using the RTCA software program of the manufacturer (xCELLigence RTCA, Roche, Germany).

\section{Antimicrobial activity studies}

Bacterial strains: In the in vitro tests, bacterial strains were obtained from the collection of the Biotechnology Institute Microbiology Department (Ankara). The minimum inhibitory concentration (MIC) of coated and uncoated MNPs (compounds) were determined by the according to the Clinical and Laboratory Institute (CLSI) (45) against the Gram positive bacteria Staphylococcus epidermidis (ATCC 12228), S. epidermidis (359984), Staphylococcus aureus (ATCC 25923), S. aureus MRSA (ATCC 43300), Streptococcus pneumoniae, Enterococcus faecalis (ATCC 29212), Acinetobacter baumannii; Gram negative Escherichia coli (ATCC 25922), E. coli (ETEC), S. Typhimurium (ATCC 14028), Klebsiella pneumoniae and the fungus Candida albicans (ATCC 90028). All test strains were grown in Mueller Hinton Broth (MHB, Merck) broth at $37^{\circ} \mathrm{C}$ with agitation $(200 \mathrm{rpm})$ if nedded. Strains were stored at $-80^{\circ} \mathrm{C}$ with the addition of $15 \%$ glycerol in growth medium.

Minimum inhibitory concentration (MIC): Briefly, MHB (Merck) was added in duplicate to the suitable amount of compounds previously dissolved in DMSO. The serial dilutions from the stock solutions of compounds were made ranging from $32 \mu \mathrm{g} / \mathrm{mL}$ to $0.25 \mu \mathrm{g} / \mathrm{mL}$. The overnight incubated bacterial suspension was diluted to $5 \times 105 \mathrm{CFU} / \mathrm{mL}$. From this suspension $45 \mu \mathrm{L}$ was inoculated into the each well. For growth and sterility control, MHB without bacteria was used for each test strain. Fungal strain was cultured for 3 days on Yeast Extract-Peptone Dextrose (YPD) agar at $30^{\circ} \mathrm{C}$. A yeast suspension of $5 \times 105$ cells (as determined by OD530) was prepared by picking and dissolving colonies in Yeast Nitrogen Base (YNB). Stock suspensions were diluted with YNB to a final concentration of $2.5 \times 103 \mathrm{CFU} / \mathrm{mL}$. From this suspension $45 \mu \mathrm{L}$ was inoculated into the each well of plates, containing coated and uncounted MNPs, individually. For growth and sterility control, YNB without yeast was used for each test strain. The microtiter plates, containing compounds and test bacteria, were incubated at $18 \mathrm{~h}$ for bacteria and $48 \mathrm{~h}$ for yeast at $37^{\circ} \mathrm{C}$. Following the incubation, 10 $\mu \mathrm{L}$ of a $0.001 \%$ resazurin was added to each well as an indicator of microbial growth. Resazurin supplemented plates were incubated at $37^{\circ} \mathrm{C}$ for 2 hours. On completion of the incubation, columns with no colour change (blue resazurin colour remained unchanged) were determined visually and scored as above the MIC value.

Growth inhibiton and Z-score: The absorbance was also measured using ELISA reader (Perkin Elmer, Victor 3) after the addition of resazurin at a $0.001 \%$ final concentration. Growth inhibition of bacteria was determined measuring absorbance between 590 and $570 \mathrm{~nm}$ (OD590-570). The percentage of the inhibition values was determined by Z-scores, calculated using the average and standard deviation of the test wells, containing microorganisms and MNPs. Samples with the inhibition value above $80 \%$ and Z-score above 2 for either replicate were classed as actives $[36,37]$. 
Acknowledgements: This study was supported by Hacettepe University Scientific Research Unit (Project no: THD2020-18806).

Author contributions: Concept - G.Ç., N.A., G.B.D., D.C.D., R.Ş.; Design - G.Ç., N.A., G.B.D., D.C.D., R.Ş.; Supervision - G.B.D., N.A., D.C.D., R.Ş.; Resources - N.A., G.B.D., D.C.D., R.Ş.; Materials - N.A., G.B.D., R.Ş., G.Ç., B.Ç., D.C.D., B.Çolak; M.A.; Data Collection and/or Processing - G.Ç., B.Ç; B.Çolak, M.A.; Analysis and/or Interpretation - N.A., D.C.D., G.B.D., R.Ş.; Literature Search - G.Ç., B.Ç., B.Çolak, M.A.; Writing - G.Ç., N.A., D.C.D., G.B.D., R.Ş.; Critical Reviews - G.B.D., D.C.D., N.A., R.Ş., G.Ç., B.Ç., B.Çolak, M.A

Conflict of interest statement: The authors declared no conflict of interest in the manuscript.

\section{REFERENCES}

[1] The top 10 causes of death. World Health Organization. https://www.who.int/news-room/factsheets/detail/the-top-10-causes-of-death (accessed September 22, 2021).

[2] Breast cancer statistics: World cancer research fund international. WCRF International 2021. https://www.wcrf.org/dietandcancer/cancer-trends/breast-cancer-statistics (accessed September 22, 2021).

[3] Moreno-Aspitia A, Perez EA. Treatment options for breast cancer resistant to anthracycline and Taxane. Mayo Clinic Proceedings 2009; 84(6): 533-545. [CrossRef]

[4] Alqaraghuli HG, Kashanian S, Rafipour R. A review on targeting nanoparticles for breast cancer. Curr Pharm Biotechnol. 2019; 20(13): 1087-1107. [CrossRef]

[5] Cancer. World Health Organization. https://www.who.int/health-topics/cancer\#tab=tab_1 (accessed September 22, 2021).

[6] Sharma VK, Singh SK. Synthesis, utility and medicinal importance of 1,2- \& -1,4-dihydropyridines. RSC Adv. 2017; 7(5): 2682-2732. [CrossRef]

[7] Fleckenstein A, Breemen Cvan. Cardiovascular Effects of Dihydropyridine-Type Calcium Antagonists and Agonists. In: Cardiovascular effects of dihydropyridine-type calcium antagonists and agonists 50 tabellen ; Bayer-Symposium IX, held at Boppard, Germany, Oct 3 - 6, 1984. Berlin u.a., Boppard: Springer; 1985. p. 3-31.

[8] Safak C, Simsek R. Fused 1,4-dihydropyridines as potential calcium modulatory compounds. Mini-Rev Med Chem. 2006; 6: 747-755. [CrossRef]

[9] Kumar RS, Idhayadhulla A, Nasser AJA, Selvin J. Synthesis and antimicrobial activity of a new series of 1,4-dihydropyridine derivatives. J Serbian Chem Soc. 2011; 76(1): 1-11. [CrossRef]

[10] Komoda H, Inoue T, Node K. Anti-inflammatory properties of azelnidipine, a dihydropyridine-based calcium channel blocker. Clin Exp Hypertens. 2010; 32(2): 121-128. [CrossRef]

[11] Milkovic L, Vukovic T, Zarkovic N, Tatzber F, Bisenieks E, Kalme Z, et al. Antioxidative 1,4dihydropyridine derivatives modulate oxidative stress and growth of human osteoblast-like cells in vitro. Antioxidants. 2018; 7(9): 1-23. [CrossRef]

[12] Gordeev MF, Patel D V., Wu J, Gordon EM. Approaches to combinatorial synthesis of heterocycles: Solid phase synthesis of pyridines and pyrido[2,3-d]pyrimidines. Tetrahedron Lett. 1996; 37(27): 4643-4646. [CrossRef]

[13] Gordeev MF, Patel D V., England BP, Jonnalagadda S, Combs JD, Gordon EM. Combinatorial synthesis and screening of a chemical library of 1,4-dihydropyridine calcium channel blockers. Bioorganic Med Chem. 1998; 6(7): 883-889. [CrossRef]

[14] Zafar AM, Iqbal A, Ashraf M, Aslam S, Naureen S, Aslam N, et al. Synthesis and in vitro cholinesterase inhibitory potential of dihydropyridine derivatives. Pak J Pharm Sci. 2019; 32(3 (Suppl.)): 1155-1162.

[15] Baydar E, Gündüz MG, Krishna VS, Şimşek R, Sriram D, Yıldırım SÖ, et al. Synthesis, crystal structure and antimycobacterial activities of 4-indolyl-1,4-dihydropyridine derivatives possessing various ester groups. Res Chem Intermed. 2017; 43(12): 7471-7489. [CrossRef] 
[16] Swarnalatha G, Prasanthi G, Sirisha N, Madhusudhana Chetty C. 1,4-Dihydropyridines: A multtifunctional molecule- a review. Int J ChemTech Res. 2011; 3(1): 75-89.

[17] Tasaka S, Ohmori H, Gomi N, Iino M, Machida T, Kiue A, et al. Synthesis and structure-activity analysis of novel dihydropyridine derivatives to overcome multidrug resistance. Bioorg Med Chem Lett. 2001; 11(2): 275-277. [CrossRef]

[18] Vijesh AM, Isloor AM, Peethambar SK, Shivananda KN, Arulmoli T, Isloor NA. Hantzsch reaction: Synthesis and characterization of some new 1,4-dihydropyridine derivatives as potent antimicrobial and antioxidant agents. Eur J Med Chem 2011; 46(11): 5591-5597. [CrossRef]

[19] Schade D, Lanier M, Willems E, Okolotowicz K, Bushway P, Wahlquist C, et al. Synthesis and SAR of bannulated 1,4-dihydropyridines define cardiomyogenic compounds as novel inhibitors of TGF $\beta$ signaling. J Med Chem 2012; 55(22): 9946-9957. [CrossRef]

[20] Ioan P, Carosati E, Micucci M, Cruciani G, Broccatelli F, S. Zhorov B, et al. 1,4-Dihydropyridine Scaffold in Medicinal Chemistry, The Story so Far And Perspectives (Part 1): Action in Ion Channels and GPCRs. Curr Med Chem. 2011; 18(32): 4901-4922. [CrossRef]

[21] Ozer EK, Gunduz MG, El-Khouly A, Simsek R, Safak C, Sara Y, et al. Synthesis of fused 1,4dihydropyridines as potential calcium channel blockers. Turkish J Biochem. 2018; 43(6): 578-586. [CrossRef]

[22] Ranjbar S, Edraki N, Firuzi O, Khoshneviszadeh M, Miri R. 5-Oxo-hexahydroquinoline: an attractive scaffold with diverse biological activities. Mol Divers 2019; 23(2): 471-508. [CrossRef]

[23] Jadhvar SC, Kasraliker HM, Goswami S V., Chakrawar A V., Bhusare SR. One-pot synthesis and evaluation of anticancer activity of polyhydroquinoline derivatives catalyzed by [Msim]Cl. Res Chem Intermed. 2017; 43(12): 7211-7221. [CrossRef]

[24] Abdel-Gawad SM, El-Gaby MSA, Heiba HI, Aly HM, Ghorab MM. Synthesis and radiation stability of some new biologically active hydroquinoline and pyrimido[4,5-b]quinoline derivatives. J Chinese Chem Soc. 2005; 52(6): 1227-1236. [CrossRef]

[25] Thumar NJ, Patel MP. Synthesis and antimicrobial activity of some new N-substituted quinoline derivatives of 1H-pyrazole. Arch Pharm (Weinheim). 2011; 344(2): 91-101. [CrossRef]

[26] Singh H, Sindhu J, Khurana JM, Sharma C, Aneja KR. A facile eco-friendly one-pot five-component synthesis of novel 1,2,3-triazole-linked pentasubstituted 1,4-dihydropyridines and their biological and photophysical studies. Aust J Chem 2013; 66(9): 1088-1096. [CrossRef]

[27] Falzone L, Salomone S, Libra M. Evolution of cancer pharmacological treatments at the turn of the third millennium. Front Pharmacol. 2018; 9: 1300. [CrossRef]

[28] Rostom SAF, Faidallah HM, Radwan MF, Badr MH. Bifunctional ethyl 2-amino-4-methylthiazole-5carboxylate derivatives: Synthesis and in vitro biological evaluation as antimicrobial and anticancer agents. Eur J Med Chem 2014; 76: 170-181. [CrossRef]

[29] Ferreira M, Sousa J, Pais A, Vitorino C. The role of magnetic nanoparticles in cancer nanotheranostics. Materials 2020; 13(2): 1-25. [CrossRef]

[30] Niemirowicz K, Durnaś B, Tokajuk G, Głuszek K, Wilczewska AZ, Misztalewska I, et al. Magnetic nanoparticles as a drug delivery system that enhance fungicidal activity of polyene antibiotics. Nanomedicine. 2016; 12(8): 2395-2404. [CrossRef]

[31] Gillis EP, Eastman KJ, Hill MD, Donnelly DJ, Meanwell NA. Applications of Fluorine in Medicinal Chemistry. J Med Chem. 2015; 58(21): 8315-8359. [CrossRef]

[32] Alkabban FM. Breast cancer. StatPearls 2021. https://www.ncbi.nlm.nih.gov/books/NBK482286/ (accessed September 22, 2021).

[33] Abotaleb M, Kubatka P, Caprnda M, Varghese E, Zolakova B, Zubor P, et al. Chemotherapeutic agents for the treatment of metastatic breast cancer: An update. Biomed Pharmacother. 2018; 101: 458-477. [CrossRef] 
[34] Hai NH, Phu ND, Luong NH, Chau N, Chinh HD, Hoang LH, et al. Mechanism for sustainable magnetic nanoparticles under ambient conditions. J Korean Phys Soc. 2008; 52(5): 1327-1331. [CrossRef]

[35] Pham XH, Hahm E, Kim HM, Son BS, Jo A, An J, et al. Silica-coated magnetic iron oxide nanoparticles grafted onto graphene oxide for protein isolation. Nanomaterials. 2020; 10(1): 1-14. [CrossRef]

[36] Curtis AE, Smith TA, Ziganshin BA, Elefteriades JA. The Mystery of the Z-Score. AORTA. 2016;4(4):124130 [CrossRef]

[37] Niemirowicz-Laskowska K, Głuszek K, Piktel E, Pajuste K, Durnaś B, Król G, et al. Bactericidal and immunomodulatory properties of magnetic nanoparticles functionalized by 1,4-dihydropyridines. Int $\mathrm{J}$ Nanomedicine. 2018; 13: 3411-3424. [CrossRef]

[38] Fahami A, Beall GW, Betancourt T. Synthesis, bioactivity and zeta potential investigations of chlorine and fluorine substituted hydroxyapatite. Mater Sci Eng C. 2016; 59: 78-85. [CrossRef]

[39] Swissadme. SwissADME. http://www.swissadme.ch/ (accessed September 22, 2021).

[40] Zhao YH, Abraham MH, Le J, Hersey A, Luscombe CN, Beck G, et al. Rate-limited steps of human oral absorption and QSAR studies. Pharm Res. 2002; 19(10): 1446-1457. [CrossRef]

[41] Fromm MF. P-glycoprotein: A defense mechanism limiting oral bioavailability and CNS accumulation of drugs. Int J Clin Pharmacol Ther. 2000; 38(2): 69-74. [CrossRef]

[42] Daina A, Zoete V. A boiled-egg to predict gastrointestinal absorption and brain penetration of small molecules. ChemMedChem 2016; 11(11): 1117-1121. [CrossRef]

This is an open access article which is publicly available on our journal's website under Institutional Repository at http://dspace.marmara.edu.tr. 